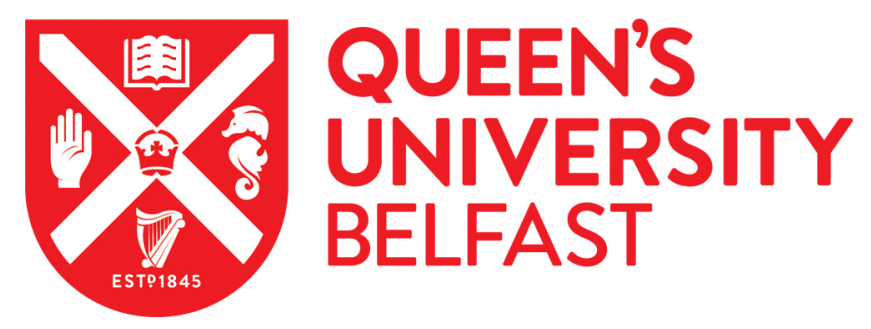

\title{
Intragenic SNP haplotypes associated with 84dup18 mutation in TNFRSF11A in four FEO pedigrees suggest three independent origins for this mutation.
}

Elahi, E., Shafaghati, Y., Asadi, S., Absalan, F., Goodarzi, H., Gharaii, N., Karimi-Nejad, M. H., Shahram, F., \& Hughes, A. (2007). Intragenic SNP haplotypes associated with 84dup18 mutation in TNFRSF11A in four FEO pedigrees suggest three independent origins for this mutation. Journal of Bone and Mineral Metabolism, 25(3), 159-164. https://doi.org/10.1007/s00774-007-0748-x

Published in:

Journal of Bone and Mineral Metabolism

Queen's University Belfast - Research Portal:

Link to publication record in Queen's University Belfast Research Portal

\section{General rights}

Copyright for the publications made accessible via the Queen's University Belfast Research Portal is retained by the author(s) and / or other copyright owners and it is a condition of accessing these publications that users recognise and abide by the legal requirements associated with these rights.

Take down policy

The Research Portal is Queen's institutional repository that provides access to Queen's research output. Every effort has been made to ensure that content in the Research Portal does not infringe any person's rights, or applicable UK laws. If you discover content in the Research Portal that you believe breaches copyright or violates any law, please contact openaccess@qub.ac.uk. 
Elahe Elahi · Yousef Shafaghati • Sareh Asadi

Farnaz Absalan • Hani Goodarzi • Nava Gharaii

Mohammad Hassan Karimi-Nejad • Farhad Shahram

Anne E. Hughes

\section{Intragenic SNP haplotypes associated with 84dup18 mutation in TNFRSF11A in four FEO pedigrees suggest three independent origins for this mutation}

Received: October 16, 2006 / Accepted: January 9, 2007

\begin{abstract}
Familial expansile osteolysis (FEO) is a rare disorder causing bone dysplasia. The clinical features of FEO include early-onset hearing loss, tooth destruction, and progressive lytic expansion within limb bones causing pain, fracture, and deformity. An 18-bp duplication in the first exon of the TNFRSF11A gene encoding RANK has been previously identified in four FEO pedigrees. Despite having the identical mutation, phenotypic variations among affected individuals of the same and different pedigrees were noted. Another 18-bp duplication, one base proximal to the duplication previously reported, was subsequently found in two unrelated FEO patients. Finally, mutations overlapping with the mutations found in the FEO pedigrees have been found in ESH and early-onset PDB pedigrees. An Iranian
\end{abstract}

E. Elahi $(\bowtie) \cdot$ S. Asadi · F. Absalan

National Institute for Genetic Engineering and Biotechnology,

Tehran-Karaj Expressway, Km 17 Pajouhesh Boulevard, Tehran,

Iran

Tel. +98-21-22181251, +98-21-44580344, +98-21-22547464;

Fax +98-21-44580399

e-mail: elahe.elahi@acnet.ir, elahe.elahi@kahyam.ut.ac.ir, elahe.

elahi@gamil.com

E. Elahi · S. Asadi · F. Absalan

Dept. of Biological Sciences, Faculty of Science, University of

Tehran, Tehran, Iran

E. Elahi

Bioinformatics Center, Institute of Biochemistry and Biophysics,

University of Tehran, Tehran, Iran

Y. Shafaghati

Genetics Research Center, University of Welfare Science and

Rehabilitation at Evin, Tehran, Iran

H. Goodarzi · N. Gharaii

Dept. of Biotechnology, Faculty of Science, University of Tehran, Tehran, Iran

M.H. Karimi-Nejad

Karimi-Nejad/Najmabadi Genetics Center, Tehran, Iran

F. Shahram

Rheumatology Research Center, Tehran University of Medical

Sciences, Tehran, Iran

A.E. Hughes

Dept. of Medical Genetics, The Queen's University of Belfast,

Belfast, UK
FEO pedigree that contains six affected individuals dispersed in three generations has previously been introduced; here, the clinical features of the proband are reported in greater detail, and the genetic defect of the pedigree is presented. Direct sequencing of the entire coding region and upstream and downstream noncoding regions of TNFRSF11A in her DNA revealed the same 18-bp duplication mutation as previously found in the four FEO pedigrees. Additionally, eight sequence variations as compared to the TNFRSF11A reference sequence were identified, and a haplotype linked to the mutation based on these variations was defined. Although the mutation in the Iranian and four of the previously described FEO pedigrees was the same, haplotypes based on the intragenic SNPs suggest that the mutations do not share a common descent.

Key words familial expansile osteolysis - TNFRSF11A . RANK $\cdot$ haplotype $\cdot$ DNA repeat sequences

\section{Introduction}

Familial expansile osteolysis (FEO; OMIM 174810) is a rare autosomal dominant disorder causing bone dysplasia. The disease was first described in 1976 [1]. Its features include early-onset hearing loss, often in childhood, tooth destruction, and progressive lytic expansion within limb bones causing pain, fracture and deformity. Its radiographic and histopathological focal skeletal defects initially resemble those observed in the active osteolytic phase of the far more common Paget's disease of bone (PDB), but evolve to expanded shell-like bones that are fat filled and almost totally devoid of bony cortex and trabecular bone pattern [2]. Defects in PDB generally affect the axial skeleton, but lesions in FEO are mostly appendicular [3].

Five families afflicted with FEO and one sporadic case of FEO have been described [4-6]. The largest of these pedigrees was from Northern Ireland, and the others were from Germany, the United States, and Spain. The disease was originally linked to chromosome 18 in the Irish family 
and, later, TNFRSF11A was identified as the causative gene in all the familial and sporadic cases [4-7]. TNFRSF11A encodes receptor activator of nuclear factor $-\kappa B$ (RANK) and was considered an appropriate candidate gene because RANK is expressed on osteoclast precursor cells and is a receptor for RANK ligand-mediated signaling affecting osteoclast formation, differentiation, and function [8]. An identical in-frame 18-base pair (18-bp) tandem duplication (84dup18; g.84_101dupCTGCTCTGCGCGCTGCTC; c.46_63dupCTGCTCTGCGCGCTGCTC) in the first exon of TNFRSF11A, affecting the signal peptide region of RANK, was identified as the disease-causing mutation in four of the families $[4,5]$. The mutation existed in the heterozygous state in affected individuals. Expression level and cleavage of the signal peptide of recombinant RANK carrying the mutation were shown to be perturbed. Functionally, the mutation caused increased RANK-mediated nuclear factor- $\kappa \mathrm{B}$ signaling in vitro [4]. The mutation in the remaining familial and sporadic cases was another 18-bp tandem duplication (83dup18; g.83_100dupGCTGCTCT GCGCGCTGCT; c.45_62dupGCTGCTCTGCGCGCT GCT), 1-bp proximal to the 84dup18 mutation in exon 1 of TNFRSF11A [6].

In addition to the FEO cases, a mutation in TNFRSF11A (75dup27; g.75_101dupGCGCTGCTGCTGCTCTGCGC GCTGCTC; c.37_63dupGCGCTGCTGCTGCTCTGC GCGCTGCTC) overlapping the mutations of the FEO patients was identified in affected members of a Japanese early-onset PDB pedigree [4]. Mutations in TNFRSF11A have not been identified in the many classic late-onset PDB patients screened [2]. Finally, a fourth mutation in TNFRSF11A (85dup15; g.84_98dupTGCTCTGCGCGC TGC; c.46_60dupCTGCTCTGCGCGCTG), overlapping with the previous three, has been reported in an Australian family afflicted with expansile skeletal hyperphosphatasia (ESH) [9]. Although ESH was thus genetically allelic to FEO, its phenotypic features were considered distinct. Specifically, ESH was characterized by widespread cortical bone thickening, absence of osteolytic lesions producing cortical thinning in the major long bones, and bouts of hypercalcemia.

Here, we report the existence of the same TNFRSF11A 84dup18 mutation (g.84_101dupCTGCTCTGCGCGCT GCTC; c.46_63dupCTGCTCTGCGCGCTGCTC) previously found in four FEO pedigrees in an Iranian FEO family. An associated haplotype is described, which suggests that the origin of the mutation in this family is distinct from that of the same mutation in the Irish, American, and German pedigrees, and that the mutation has at least three different origins.

\section{Materials and methods}

Subjects

This study was performed after approval from the Ethics Review Board of the National Institute for Genetic Engineering and Biotechnology (Iran) and with informed con-

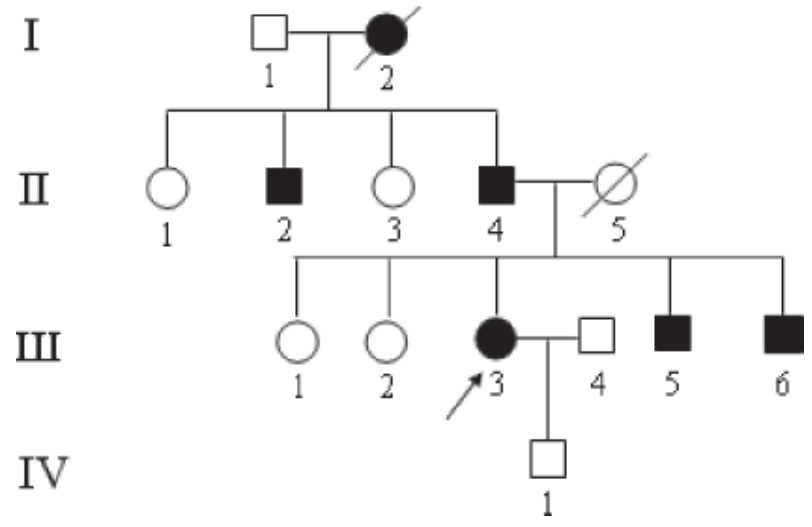

Fig. 1. Pedigree of Iranian familial expansile osteolysis (FEO) family

sent of pedigree members in accordance with the Declaration of Helsinki Guidelines. The proband is a 31-year-old woman of an Iranian FEO pedigree that has previously been described, with emphasis on otological features of the patients [10]. Disease in the pedigree, which contains six affected individuals distributed in three generations, shows autosomal dominant inheritance (Fig. 1). Members of the pedigree not affected with FEO were healthy. Family members report no consanguinity.

The phenotype of the proband is more severe than that of other affected members of the pedigree. Some clinical features not presented in the previous report on the pedigree were detected in a thorough examination of the proband at the age of 31 [10]. Whole-body Tc99-MBP (technetium 99-methylene biphosphonate) scan revealed multiple sites of increased activity, particularly in the calvarium, facial bones, clavicles, long bones of the extremities, left fifth metatarsal bone, left foot second phalangeal bone, and medial tarsal joints. Bone densitometry by dualenergy X-ray absorptiometry (DXA) showed low bone mass in the wrist ( $T$-score, -2.6$)$ and lumbar $(T$-score, -3.4$)$ regions. Bone density of the femoral neck was normal. Radiography showed anterior bowing of the tibia and coarse longitudinal trabeculation in the metaphysis (Fig. 2a). Local lesions in the proximal part of the right tibia and degenerative changes in both knee joints were observed. Hand Xrays revealed diffuse expansion of bones and a cystic pattern of coarse trabeculation (Fig. 2b). Radiographs of the pelvis were normal, but X-rays of the skull indicated increased thickness of the occipital bone (Fig. 2c). Treatment of this patient with alendronate has been initiated.

A recent medical examination on other affected pedigree members was not performed, either because they were not available or they would not consent. Nevertheless, some information is available from previous medical records or conversations. Individuals III:3 and III:6 have more sever phenotypes than the other affected individuals. Phenotypic variations within and between FEO pedigrees have been reported in other studies [2]. Although the clinical features of the Iranian pedigree most closely resemble those of FEO, hand and skull involvement has previously been associated 
Fig. 2. Radiologic findings of proband of Iranian FEO pedigree. a X-ray shows anterior bowing of both tibia with coarse longitudinal trabeculation in their metaphysis. A lucent defect $(2.5 \mathrm{~cm} \times 1.5 \mathrm{~cm})$ in the proximal part of the right tibia and degenerative changes in both knee joints are seen. b Diffuse expansion of hand bones with coarse trabeculation are visible, and cystic changes without subperiosteal resorbion are noted. c Skull radiograph shows increased thickness of occipital part of cranial bones
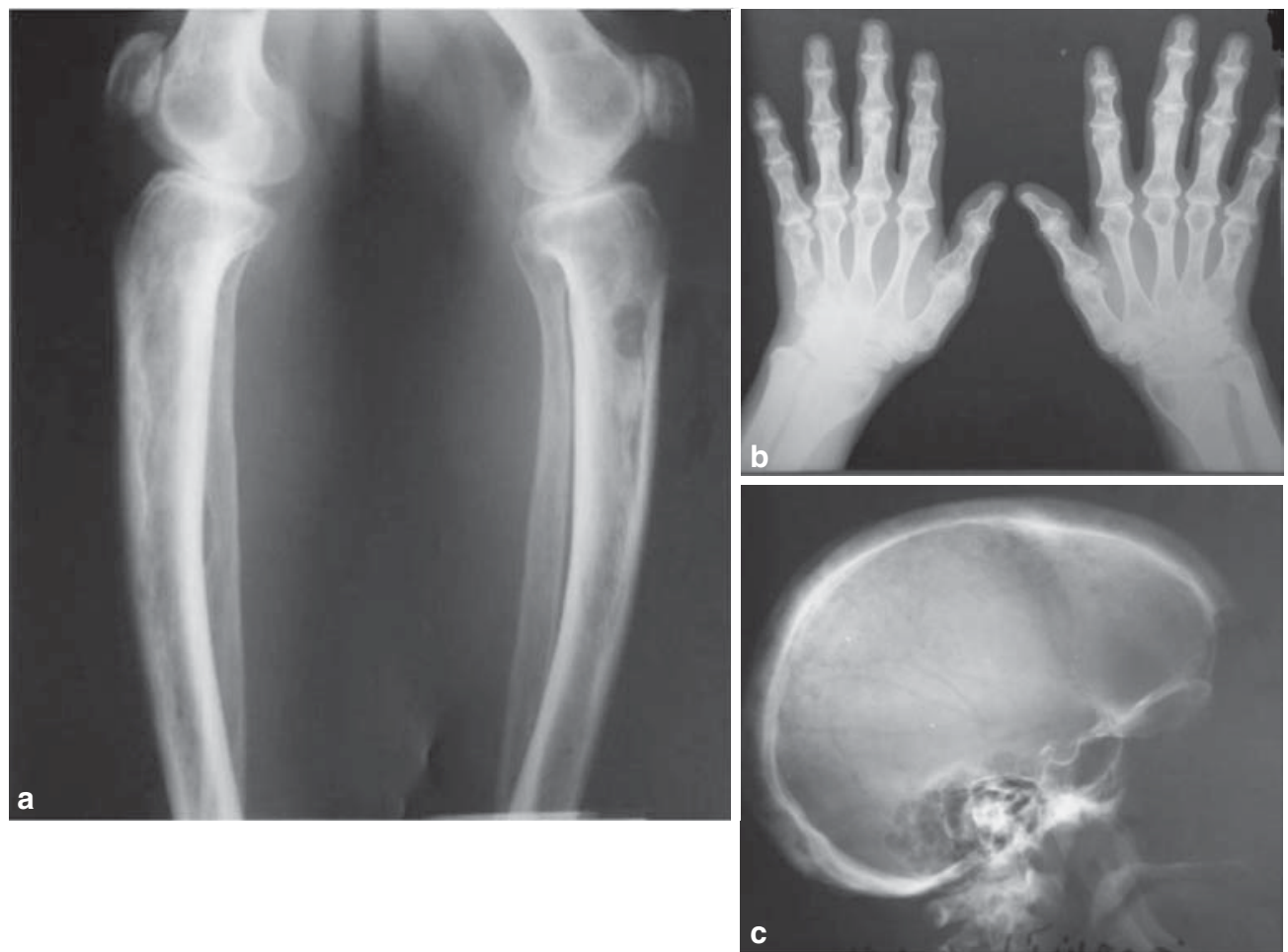

Table 1. Phenotypic features of familial expansile osteolysis (FEO) patients

\begin{tabular}{|c|c|c|c|c|c|c|c|}
\hline Nationality & $\begin{array}{c}\text { Spanish } \\
{[5]}\end{array}$ & $\begin{array}{l}\text { Irish } \\
{[2,4]}\end{array}$ & $\begin{array}{c}\text { American } \\
{[2,4]}\end{array}$ & $\begin{array}{c}\text { German } \\
{[2,4]}\end{array}$ & $\begin{array}{l}\text { Sporadic } \\
\text { [6] }\end{array}$ & $\begin{array}{c}\text { American } \\
{[6]}\end{array}$ & $\begin{array}{c}\text { Iranian } \\
\text { (present study) }\end{array}$ \\
\hline $\begin{array}{l}\text { Deafness in } \\
\text { childhood }\end{array}$ & Yes & Yes & Yes & NR & Yes & Yes & Yes \\
\hline Tooth loss & $\begin{array}{c}\text { Yes } \\
\text { (in childhood) }\end{array}$ & $\begin{array}{c}\text { Yes } \\
\text { (in childhood) }\end{array}$ & $\begin{array}{c}\text { Yes } \\
\text { (in childhood) }\end{array}$ & NR & $\begin{array}{c}\text { Yes } \\
\text { (late twenties) }\end{array}$ & $\begin{array}{c}\text { Yes } \\
\text { (during twenties) }\end{array}$ & Yes \\
\hline Hand involvement & No & No & No & Yes & No & No & Yes \\
\hline Pelvic involvement & No & No & No & NR & No & No & No \\
\hline Skull involvement & No & No & No & NR & No & No & Yes \\
\hline $\begin{array}{l}\text { Pathological } \\
\text { fracture }\end{array}$ & No & NR & NR & NR & Yes & NR & Yes \\
\hline Osteolytic lesions & $\begin{array}{l}\text { Only in } 2 \text { of } 14 \\
\text { affected }\end{array}$ & Yes & Yes & Yes & Yes & NR & Yes \\
\hline Elevated SAP & NR & Yes & Yes & NR & Yes & Yes & Yes \\
\hline Elevated UHP & NR & NR & NR & NR & NR & Yes & NR \\
\hline
\end{tabular}

NR, not reported; SAP, serum alkaline phosphatase; UHP, urinary hydroxyproline

with ESH and early-onset PDB and generally not with FEO, emphasizing the merging phenotypic features of these diseases [11].

Table 1 compares the reported phenotypic features of genetically analyzed FEO patients thus far reported. Even childhood deafness, the earliest sign of FEO in most patients, does not manifest in all affected individuals (e.g., III:5 in Iranian pedigree showed no sign of deafness at age 28). Although early-onset deafness was not observed in most affected members of the early-onset PDB pedigree carrying a mutation in TNFRSF11A, it was reported in one of the patients [11]. Similarly, tooth loss is generally in childhood in FEO and later in ESH and PDB, but the reverse pattern has also been reported in some cases $[6,11]$.

\section{DNA analysis}

DNA was prepared from the leukocytes of the peripheral blood of individuals II:4, III:2, III:3, III:6, and IV:1. Exon 1 of TNFRSF11A was amplified by the polymerase chain reaction (PCR) using forward primer 5'-TGGGGTGCG GCAAGGCAGGAG-3' and reverse primer $5^{\prime}$-AAGGC GGAGGAGCCAGGATGC-3'. Exon 1 amplicons were electrophoresed on agarose gels. The remaining 9 exons of TNFRSF11A were PCR amplified only from DNA of the proband. (Primer sequences are available upon request.) All DNA bands observed upon electrophoresis of exon 1 PCR products of affected individuals were eluted and sequenced using the ABI Big Dye terminator chemistry. In all, 6217 nucleotides in the DNA of the proband were 
Fig. 3. Electrophoretic pattern of polymerase chain reaction (PCR)-amplified exon 1 of FEO pedigree members. $\mathrm{M}$, molecular weight markers; lanes $1,2,3$, amplicons of affected individuals II:4, III:3, and III:6, respectively; lanes $4,5,6$, amplicons of nonaffected individuals III:2, IV:1, and an unrelated individual, respectively; WT, wild-type allele; MUT, mutant allele, HD, heteroduplex

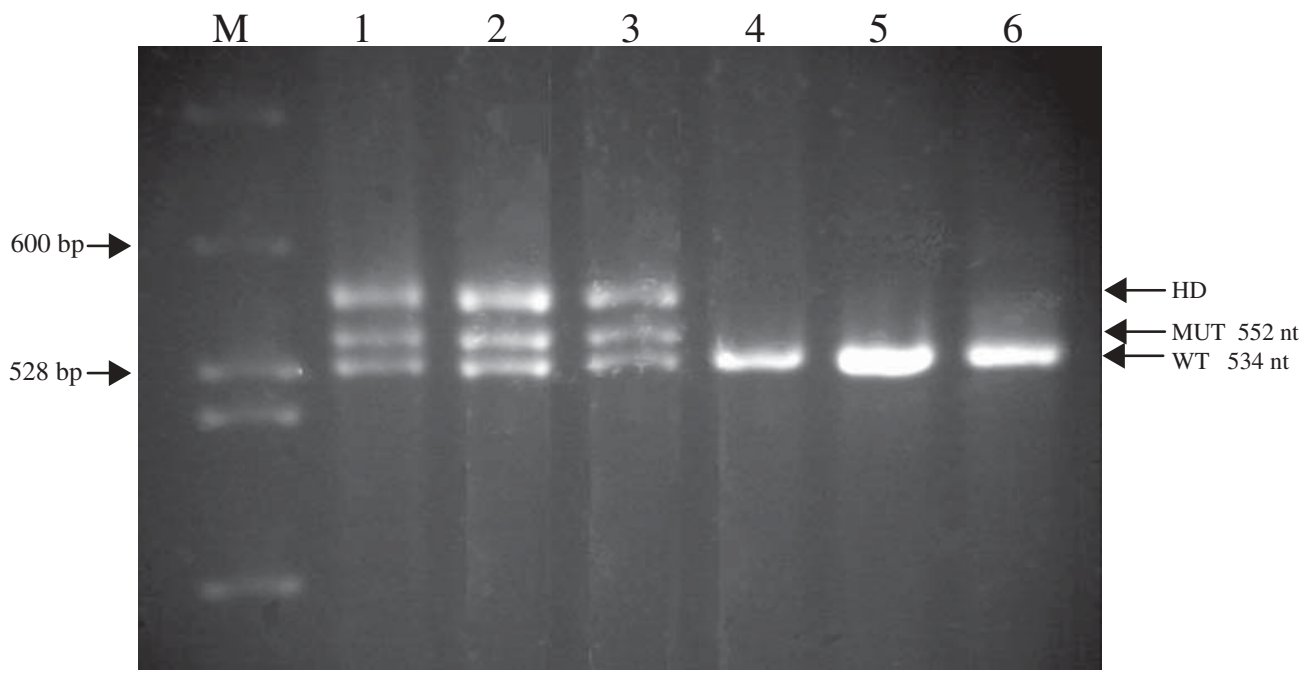

sequenced, including 303 nucleotides upstream of the transcriptional initiation site, the entire $5^{\prime}$-noncoding and 252 nucleotides of the 3'-nontranslated region. Sequence variations were determined by comparison with the NCBI genomic DNA reference sequence (NT_025028), cDNA reference sequence (NM_003839), and protein reference sequence (NP_003830), using Sequencher software (Gene Codes Corporation, Ann Arbor, MI, USA). Effects of sequence changes on splicing were predicted by comparison with known canonical splice site motifs (http://www.fruitfly. org/seq_tools/splice.html). For determination of the phase of two variations found in the DNA of the proband by sequencing, linkage analysis was done by RFLP using Aci I (Cinnagen, Tehran, Iran).

\section{Results}

The electrophoresis pattern of the PCR product of exon 1 of the TNFRSF11A gene in DNA of affected family members was consistent with there being an insertion in one allele of each of the individuals (Fig. 3). Sequencing showed that exon 1 of the proband and afflicted individuals II:4 and III:6 carried an 18-bp tandem duplication, g.84_101dupCT GCTCTGCGCGCTGCTC (c.46_63dupCTGCTCTGCGC GCTGCTC) in the heterozygous state (Fig. 4); this is the same duplication as reported in four previously studied FEO pedigrees [4,5]. Both alleles of the unaffected 28-yearold sister (III;2) of the proband were wild type, as were the alleles of the 6-year-old offspring of the proband.

In addition to the disease-causing mutation, the DNA sequence of the proband showed eight other sequence variations as compared to the TNFRSF11A genomic sequence NT_025028. One variation caused an amino acid alteration, another resulted in a synonymous codon change, and six were intronic. The variations are listed in Table 2. None of the variations were predicted to affect splicing. The variations g.34694C $>$ T (c.575C $>$ T; p.A192V), IVS5-17C > T, and IVS6-151G $>A$ were present in the heterozygous state, and the others were homozygous. Linkage analysis by RFLP on

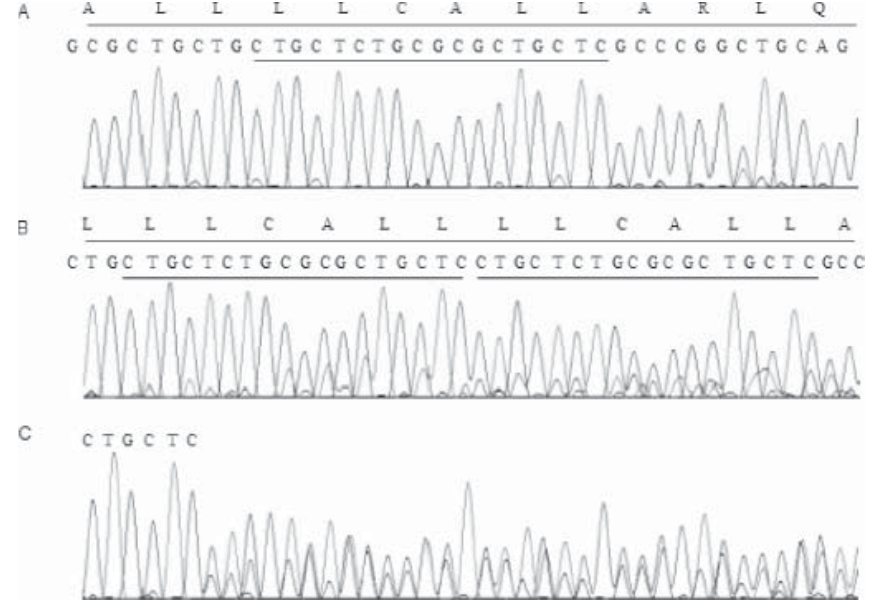

Fig. 4. Sequence chromatograms of exon 1 amplicon of proband. A DNA of wild-type allele; B DNA of mutated allele; C DNA of heteroduplex band. Relevant sequences are underlined, and coded amino acids are indicated above chromatograms $\mathbf{A}$ and $\mathbf{B}$

the DNAs of individuals II:4, III:2, III:3, and III:6 showed g.34694C (c.575C; p.192A) was linked to the mutationcarrying allele of TNFRSF11A. The same analysis proved to be uninformative for the variation IVS5-17C $>\mathrm{T}$ (not shown). Phase analysis was not done for IVS6-151G $>$ A.

\section{Discussion}

A fifth FEO pedigree carrying the disease causing g.84_101dupCTGCTCTGCGCGCTGCTC duplication (84dup18) in TNFRSF11A is reported here. The 83dup18 mutation found in two other unrelated FEO cases has the same effect as 84dup18 at the protein level; both result in the same six amino acid insertion in the signal peptide of RANK [6]. The finding of either of two mutations that result in an identical protein alteration in all the FEO cases suggests this particular alteration may uniquely result in the FEO phenotype. Other mutations in the gene may cause 
Table 2. Variations in TNFRSF11A in FEO pedigrees

\begin{tabular}{|c|c|c|c|c|c|c|c|c|}
\hline \multicolumn{3}{|c|}{ SNP } & \multirow[t]{2}{*}{$\mathrm{rs}^{\# \mathrm{c}}$} & \multirow{2}{*}{$\begin{array}{l}\text { Nucleotide } \\
\text { in reference } \\
\text { sequence }\end{array}$} & \multicolumn{4}{|c|}{$\begin{array}{c}\text { Linkage to mutated allele in } \\
\text { FEO pedigrees }\end{array}$} \\
\hline $\begin{array}{l}\text { g. position } \\
\text { (NT_025028) }\end{array}$ & $\begin{array}{l}\text { c. position }{ }^{2} \\
\text { (NM_003839) }\end{array}$ & $\begin{array}{l}\text { p. position } \\
\text { (NP_003830) }\end{array}$ & & & Irish & US & German & Iranian \\
\hline g.118 & IVS1+5 & & & G & A & G & $\mathrm{G}$ & $\mathrm{T}$ \\
\hline g. 34624 & IVS5-17 & & 6567272 & $\mathrm{C}$ & $\mathrm{C}$ & $?$ & ? & $\mathrm{C} / \mathrm{T}^{\mathrm{d}}$ \\
\hline g.34694 & c. 575 & A192 & 1805034 & $\mathrm{C}$ & $\mathrm{C}$ & $?$ & ? & $\mathrm{C}^{\mathrm{e}}$ \\
\hline g.34814 & IVS6+79 & & 9653064 & G & G & $?$ & $?$ & A \\
\hline g.36215 & IVS6-151 & & 8099222 & $\mathrm{G}$ & $?$ & $\mathrm{G}$ & $?$ & $\mathrm{G} / \mathrm{A}^{\mathrm{d}}$ \\
\hline g. 36670 & IVS7+192 & & & $\mathrm{T}$ & ? & $?$ & ? & $\mathrm{C}$ \\
\hline g.36691 & IVS7+213 & & 7239667 & $\mathrm{G}$ & ? & $?$ & ? & $\mathrm{C}$ \\
\hline g.43536 & c. 933 & T311 & 8092336 & A & $\mathrm{G}$ & G & $?$ & $\mathrm{G}$ \\
\hline
\end{tabular}

${ }^{a}$ Positions where nucleotide definitely differ between two or more pedigrees are shown in bold

" "A" of AUG initiation codon is considered +1

${ }^{c}$ Reference numbers (rs\#) of variations registered in build 125 of NCBI SNP database (http://www.ncbi.nlm.nih.gov)

${ }^{\mathrm{d}}$ Phase not established

${ }^{\mathrm{e}}$ Nucleotide on allele not carrying the duplication mutation was $\mathrm{T}$

diseases with related and overlapping yet distinct phenotypic features, such as early-onset PDB and ESH [4,9]. Alternatively, it is possible that environmental factors and the genetic background of the patients significantly contribute to the phenotypic variations of patients carrying the different mutations in TNFRSF11A [12]. It will be interesting to learn the genetic cause of FEO in a recently reported FEO pedigree from the Czech Republic [13].

The haplotype associated with the mutated TNFRSF11A allele in the Iranian pedigree, defined by six intragenic single nucleotide variations, five of which were present in the homozygous state, can unambiguously be described as $\mathrm{T}_{\mathrm{g} .118}$

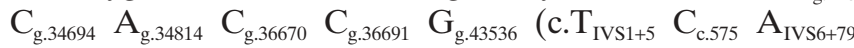
$\mathrm{C}_{\mathrm{IVS} 7+192} \mathrm{C}_{\mathrm{IVS} 7+213} \mathrm{G}_{\mathrm{c} 933}$ ). There has previously been only one report on single nucleotide variations associated with the mutated TNFRSF11 $A$ allele in FEO pedigrees [4]. In Table 2 , nucleotides at positions corresponding to some of the variant positions found in the Iranian pedigree are shown in three other FEO pedigrees carrying the same 84dup18 mutation. The pedigrees do not share the same allele at positions IVS1+5 and IVS6+79. Most interestingly, position IVS1+5, close to the $5^{\prime}$-splice site of intron 1 , was A in the Irish pedigree, $\mathrm{G}$ in the American and German pedigrees, and $\mathrm{T}$ in the Iranian pedigree. This finding implies that the common mutation in the Irish, American, and Iranian pedigrees each arose independently. The mutated allele of the American and German pedigrees may have a common origin based on this analysis. $\mathrm{G}$ is found at position 5 of the $5^{\prime}$-splice site in more than $75 \%$ of human introns, and A and $\mathrm{T}$ are both relatively rare alleles at that position [14]. The independent origin of the mutation in the Irish and Iranian pedigrees is confirmed by the difference of sequence at position IVS6+79. Knowledge of SNP nucleotides in TNFRSF11A and the haplotypes they define will be useful for determining common or independent origins of FEO mutations to be identified in other pedigrees in the future.

The 84dup18 duplication observed in the FEO pedigrees and the 27bp duplication in the early-onset PDB pedigree were previously suggested to have arisen by reverse slippage during DNA replication [4]. A model that suggests the role of a stable secondary structure of the DNA in facilitat- ing generation of the tandem duplications has also been presented [6]. The proposed independent origins of the identical duplication in at least three different FEO pedigrees suggest that the duplication occurs at a mutation hotspot and is consistent with these models. The repetitive and G/C-rich nature of the sequences surrounding the close and partly overlapping duplications of the FEO, early-onset $\mathrm{PDB}$, and ESH duplications are likely to promote mutation events [15]. The preponderance of CTG repeats may be particularly important in this regard [16].

Acknowledgments The authors are grateful to the members of the Iranian FEO pedigree who agreed to participate in this research. This research was funded by the International Institute for Genetic Engineering and Biotechnology, Tehran, Iran.

\section{References}

1. Osterberg PH (1976) An unusual familial disorder of bone: response to calcitonin. In: Kanis JA (ed) Bone Disease and Calcitonin. Armour Pharmaceutical, London, pp 181-185

2. Whyte MP, Reinus WR, Podgornik MN, Mills BG (2002) Familial expansile osteolysis (excessive RANK effect) in a 5-generation American kindred. Medicine (BaHim) 81:101-121

3. Crone MC, Wallace RGH (1990) The radiographic features of familial expansile osteolysis. Skelet Radiol 19:245-250

4. Hughes AE, Ralston SH, Marken J, Bell C, MacPherson H, Wallace RGH, van Hul W, Whyte MP, Nakatsuka K, Hovy L, Anderson DM (2000) Mutations in TNFRSF11A, affecting the signal peptide of RANK, cause familial expansile osteolysis. Nat Genet 24:45-48

5. Palenzuela L, Vives-Bauza C, Fernández-Cadenas I, Meseguer A, Font N, Sarret E, Schwartz S, Andreu AL (2002) Familial expansile osteolysis is a large Spanish kindred resulting from an insertion mutation in the TNFRSF11A gene. J Med Genet 39:e67

6. Johnson-Pais TL, Singer FR, Bone HG, McMurray CT, Hansen MF, Leach RJ (2003) Identification of a novel tandem duplication in exon 1 of the TNFRSF11A gene in two unrelated patients with familial expansile osteolysis. J Bone Miner Res 18: 376-380

7. Hughes AE, Shearman AM, Weber JL, Barr RJ, Wallace RG, Osterberg PH, Nevin NC, Mollan RA (1994) Genetic linkage of familial expansile osteolysis to chromosome 18. Hum Mol Genet 3:359-361

8. Hsu H, Lacey DL, Dunstan CR, Solovyev I, Colombero A, et al. (1999) Tumor necrosis factor receptor family member RANK 
mediates osteoclast differentiation and activation induced by osteoprotegerin ligand. Proc Natl Acad Sci USA 96:35403545

9. Whyte MP, Hughes AE (2002) Expansile skeletal hyperphosphatasia is caused by a 15-base pair tandem duplication in TNFRS $F 11 A$ encoding RANK and is allelic to familial expansile osteolysis. J Bone Miner Res 17:26-29

10. Daneshi A, Shafeghati Y, Karimi-Nejad MH, Khosravi A, Farhang F (2005) Hereditary bilateral hearing loss caused by total loss of ossicles: a report of familial expansile osteolysis. Otol Neurotol 26:237-240

11. Nakatsuka K, Nishizawa Y, Ralston SH (2003) Phenotypic characterization of early onset Paget's disease of bone caused by a 27-bp duplication in the TNFRSF11A gene. J Bone Miner Res 18:13811385
12. Daroszewska A, Ralston SH (2005) Genetics of Paget's disease of bone. Clin Sci 109:257-263

13. Marik I, Marikova A, Hankova E, Kozlowski K (2006) Familial expansile osteolysis - not exclusively an adult disorder. Skeletal Radiol 10:1-4

14. Zhang MQ (1998) Statistical features of human exons and their flanking regions. Hum Mol Genet 7:919-932

15. Ball EV, Stenson PD, Abeysinghe SS, Krawczak M, Cooper DN, Chuzhanova NA (2005) Microdeletions and microinsertions causing human genetic disease: common mechanisms of mutagenesis and the role of local DNA sequence complexity. Hum Mutat 26:205-213

16. McMurray CT (1999) DNA secondary structure: a common and causative factor for expansion in human disease. Proc Natl Acad Sci USA 96:1823-1825 